\title{
Dental caries and plaque formation from diets containing sucrose or glucose in gnotobiotic rats infected with Streptococcus strain IB-1600
}

\author{
By T. H. GRENBY, FRANCES M. PATERSON AND R. A. CAWSON \\ Department of Oral Medicine and Pathology, Guy's Hospital, London SEI $9 R T$
}

(Received 7 March I972-Accepted $24 \mathfrak{7}$ uly 1972)

\begin{abstract}
I. Techniques were devised for the operation of a new small-scale gnotobiotic rat unit.
2. The unit was then used to compare the cariogenicity of sucrose and glucose under carefully controlled conditions in the presence of a single strain of a streptococcus, as gnotobiotic experiments by other workers had given conflicting results.

3. Streptococcus IB-r6oo was implanted into thirty-four rats, which were then fed on highsugar dicts under gnotobiotic conditions for 5 or 8 weeks from weaning. The level of caries was significantly higher on the sucrose than on the glucose diet, but therc was no significant difference in the extent of soft coronal dental plaque.
\end{abstract}

There is good evidence that dietary sucrose produces more caries than glucose in conventional laboratory animals (e.g. Shafer, x949; Gustafson, Stelling, Abramson \& Brunius, 1955; Grenby, 1963) and also in animals infected with a caries-inducing Streptococcus (Krasse, I965) and in 'relatively gnotobiotic' animals (Guggenheim, König, Herzog \& Mühlemann, ı966). Very few results have been reported, however, on the effects of these dietary sugars on dental caries and plaque formation in animals reared germ-free and then mono-infected with a caries-inducing micro-organism.

Such gnotobiotic animals have been used in dental research mainly to test whether specific micro-organisms can cause or transmit dental caries (e.g. Orland, Blayney, Harrison, Reyniers, Trexler, Ervin, Gordon \& Wagner, r955; Fitzgerald \& Keyes, I960; Gibbons, Berman, Knoettner \& Kapsimalis, ıg66; Zinner, Jablon, Aran \& Saslaw, I966; Rosen, Lenney \& O'Malley, i968; Blackmore \& Green, I971). In the small number of trials comparing sucrose and glucose diets under gnotobiotic conditions there is disagreement on the relative cariogenicity of the two sugars. Rosen (1969) found that glucose in the diet caused more caries than sucrose in gnotobiotic rats infected with a lactobacillus or any of three different strains of streptococci, whereas Fitzgerald (1968) found that glucose produced no caries, but sucrose was cariogenic in the presence of several different streptococci.

Thus gnotobiotic experiments comparing the cariogenicity of sucrose and glucose have given variable results, though it is usually accepted that sucrose is more cariogenic under conventional conditions. The purpose of the following trials was to compare the cariogenicity of the two sugars under carefully controlled conditions, using a single strain of micro-organism (Streptococcus IB-1600), to reduce the variables that might affect the issue. The aim was also to test initially the efficiency of a new germfree and gnotobiotic rat unit to be used for dental research. 


\section{METHODS}

\section{Gnotobiotic techniques}

The methods were adapted from germ-free techniques used for various clinical or research purposes at other centres in Britain. Apart from some details given by Cook, Tuffrey \& Barnes (1968) and Dinsley (1967), very little published information on these methods is available, so they are described here in some detail.

The rats were kept in plastic cages with stainless-steel grids at the top and the bottom, enclosed in isolators of a modified Trexler (r964) pattern (Spembly Technical Products, Sittingbourne, Kent), consisting essentially of an enclosed plastics-film tent under positive pressure. Air was continuously blown through by an electrical pump, giving four to five changes of air per $h$. Both the inlet and outlet were filtered through external-fitting cylindrical filters with glass-fibre elements to keep out bacteria, spores and other particulate matter. All manipulations inside the isolators were done through long, rubber gloves sealed into the walls of the isolator. Each isolator had a cylindrical glass-fibre entry port of $305 \mathrm{~mm}$ diameter, fitted with inner and outer caps.

In setting up, the isolator was initially sterilized by washing with a mixture of $\mathrm{x} \%$ formalin and Teego (10 ml/l) (Atlas Laboratories, Manchester 19), followed by spraying with peracetic acid $(2 \circ \mathrm{g} / 1)$ (Laporte Industries Ltd, Luton, Beds.). Cages, food hoppers, water-bottles, food, sawdust for placing under the grids of the cages, and other items to be used inside the isolators were double-wrapped and heat-sealed in polyethylene bags and sterilized by $\gamma$-irradiation at $5 \mathrm{Mrd}$ (Package Irradiation Plant, UKAEA, Wantage, Berks.). They were introduced into the isolator by removing the outer wrapping, sterilizing them in the port chamber by thorough spraying with fresh peracetic acid $(20 \mathrm{~g} / \mathrm{l})$, then taking the articles into the interior of the isolator, not less than $0.5 \mathrm{~h}$ after spraying, by means of the long, rubber gloves. Items not sterilized by $\gamma$-irradiation were first soaked in a solution of $\mathbf{I} \%$ formalin-Teego ( $10 \mathrm{ml} / \mathrm{l}$ ), then rinsed with distilled water, and finally sprayed with peracetic acid (20 g/1). Autoclaved, canned drinking-water (Smedley's Ltd, Whyteleafe, Surrey) was sterilized in this way, but all food was irradiated.

\section{Animals and their treatment}

The rats belonged to the Fisher albino strain which had been random-bred. Breeding pairs were kindly supplied germ-free by the Ministry of Defence Microbiological Research Establishment, Porton Down, Wiltshire. The breeding stock was kept in one isolator and the young were transferred to a separate one at weaning (about $28 \mathrm{~d}$ of age) for experimental use. The transfer was achieved by linking the entry ports of the two isolators, sterilizing the enclosed area formed, and passing the young germ-free rats through it quickly.

Once in the experimental isolator, the rats were inoculated with a $4^{8 \mathrm{~h}}$ liquid bacterial culture by swabbing it into their mouths and also by infecting the drinkingwater and food hoppers. A total of five litters were divided into equal groups, matched as evenly as possible for age and litter, to be fed on the two different experimental 
diets, then at the end of 5 or 8 weeks they were taken out of the isolator and killed. They were either examined immediately or stored at $-25^{\circ}$.

The jaws were dissected out and first examined for plaque by immersing in basic fuchsin-disclosing solution $(5 \mathrm{~g} / 1)$, gently rinsing in running water, then scoring soft plaque on the molar teeth on a $\sigma_{-5}$ scale under a magnification of $\times 25$. This was based on a modification of the Oral Debris Index of Greene \& Vermillion (I960), as used on baboons (Grenby, 197I), with a score of o for a tooth with completely clean surfaces, and 5 for a tooth in which the buccal and lingual surfaces were completely covered by plaque. All the scores were then added to give a plaque score for each animal.

Dental caries in the mandibular molars was assessed by the occlusal grinding method of Shaw, Schweigert, McIntire, Elvehjem \& Phillips (1944), as modified by Grenby \& Hutchinson (1969) and Grenby (r97o). Lesions in the six main, molar fissures were scored on a scale of $I-5$; other lesions were scored as grade $I$ or grade 2 . A caries score was compiled for each animal by adding the figures for both mandibles.

\section{Bacteria and monitoring}

Only one strain of cariogenic Streptococcus was used in these first experiments. This was the Ingbritt strain of human origin described by Krasse (1966). A selected substrain IB-I600, resistant to streptomycin ( $1600 \mu \mathrm{g} / \mathrm{ml}$ medium) to facilitate identification (Edwardsson, I968), was kindly supplied by Dr W. H. Bowen of the Royal College of Surgeons. It could be grown aerobically or anaerobically on a variety of solid media including blood agar, tryptone soya-bean agar and mitis-salivarius agar, and in liquid media, such as tryptone soya-bean broth, brain-heart infusion, thioglycollate and Todd-Hewitt broth, with or without the appropriate concentration of streptomycin.

During the experiments oral and faecal samples were taken at intervals to check that the test organism had persisted and that other micro-organisms had not gained entry. The breeding isolator was also monitored regularly to check that it remained germ-free. The media used for this included tryptone soya-bean broth and agar, thioglycollate, blood agar, mitis-salivarius agar, Sabouraud media and brain-heart infusion. The media were inoculated with the samples in a laminar air-flow cabinet, and incubated aerobically at $37^{\circ}$ and at room temperature, and anaerobically at $37^{\circ}$ for periods of up to 2 weeks; the media were examined daily for signs of bacterial or fungal growth.

\section{Diets}

The breeding rats were fed on research animal diet no. 86 (E. Dixon \& Sons Ltd, Ware, Herts.). The experimental diets contained $(\mathrm{g} / \mathrm{kg})$ : cither sucrose (caster sugar) or glucose 460; white flour 200; Complan (Glaxo Laboratories Ltd, Greenford, Middx) 320; and desiccated liver (Armour Pharmaceutical Co. Ltd, Eastbourne, Sussex) 20. 'These diets were given ad lib. as dry powders for periods of 5 or 8 weeks from weaning; drinking-water was always available to the animals. 
Table I. Plaque scores of rats inoculated with Streptococcus $I B$-I600 and fed on diets containing $460 \mathrm{~g}$ sugar (sucrose or glucose) $/ \mathrm{kg}$

\begin{tabular}{|c|c|c|c|c|}
\hline & \multicolumn{2}{|c|}{ 5-week expt } & \multicolumn{2}{|c|}{ 8-week expt } \\
\hline & Sucrose diet & Glucose diet & Sucrose diet & Glucose diet \\
\hline $\begin{array}{l}\text { No. of animals } \\
\text { Mean plaque score } \\
\text { SE of mean } \\
\text { Significant difference between means }\end{array}$ & $\begin{array}{ll} & 5 \\
& \\
& \\
\pm & \\
& \\
& P>\end{array}$ & $\begin{array}{c}9 \\
7 \cdot 4 \\
\pm 0 \cdot 7\end{array}$ & $\begin{array}{l}12 \\
9 \cdot 2 \\
\pm 0 \cdot 9 \\
0 \cdot 1>F\end{array}$ & $\begin{array}{c}8 \\
6 \cdot 9 \\
\pm 0 \cdot 4 \\
\mathrm{NS}^{5}\end{array}$ \\
\hline & NS, not $\mathrm{s}$ & cant. & & \\
\hline
\end{tabular}

Table 2. Caries scores of rats inoculated with Streptococcus $I B-\mathrm{I} 600$ and fed on diets containing $460 \mathrm{~g}$ sugar (sucrose or glucose)/kg

No. of animals Mean caries score SE of mean

Difference between means

\begin{tabular}{|c|c|c|c|}
\hline \multicolumn{2}{|c|}{ 5-weck expt } & \multicolumn{2}{|c|}{ 8-week expt } \\
\hline Sucrose diet & Glucose diet & Sucrose diet & Glucose diet \\
\hline 5 & 9 & $\mathrm{I} 2$ & 8 \\
\hline $2 I \cdot 8$ & I 5.4 & $40 \cdot 1$ & $24 \cdot 5$ \\
\hline \multicolumn{2}{|c|}{$P=0.05$} & \multicolumn{2}{|c|}{$P<0.002$} \\
\hline
\end{tabular}

\section{EXPERIMENTAL AND RESULTS}

\section{Preliminary trials}

Six germ-free rats which were fed on the highly cariogenic ( $460 \mathrm{~g}$ sucrose $/ \mathrm{kg})$ diet for 5 or 8 weeks developed no dental plaque, and staining with basic fuchsin revealed only occasional discontinuous traces of pellicle along the gingival margins of the molars. These animals developed no caries.

When another group of six germ-free rats were taken out of the isolators, caged with conventional rats of the caries-active Wistar and Osborne-Mendel strains (see Grenby, 1967 ), and fed on a $460 \mathrm{~g}$ sucrose $/ \mathrm{kg}$ diet for 5 weeks from weaning, the mean plaque score was $\mathrm{I}_{5} .7\left(\mathrm{SE} \pm \mathrm{I} \cdot 0\right.$ ) and the mean caries score was $30^{\circ} 3(\mathrm{SE} \pm \mathrm{I} \cdot 5)$ with an average per rat of $3^{\cdot 8}$ grade I lesions, $7^{\cdot 2}$ grade 2 lesions and $4^{\circ}$ o gross lesions (grade 3 or more).

\section{Sucrose v. dextrose in gnotobiotes}

Streptococcus IB-I600 was implanted into thirty-four weanling rats, which were divided into two groups of seventeen, one fed on the sucrose diet and the other on the glucose diet. The streptomycin-resistant Streptococcus persisted in the animals throughout the experimental period of 5 or 8 weeks.

\section{Plaque}

At the end of the experimental periods of both 5 and 8 weeks, soft deposits which stained with basic fuchsin were observed along the gingival margins of the molar teeth, spreading upwards towards the crowns, especially on the buccal surfaces. In some animals a light, discontinuous pellicle covered parts of the cusps. The appearance 
Table 3. Numbers of carious lesions in mandibular molars of rats inoculated with Streptococcus strain $1 B-1600$ and fed on diets containing $460 \mathrm{~g}$ sugar (sucrose or dextrose) $/ \mathrm{kg}$

No. of animals

$\begin{array}{cc}\text { Sucrose diet } & \text { Dextrose diet } \\ 5 & 9 \\ 6.0 & 6.4 \\ 6 \cdot 4 & 4.3 \\ \text { I.0 } & 0.1 \\ - & - \\ -\cdots & -- \\ \text { I3.4 } & \text { I0.8 } \\ \text { I.0 } & 0.1 \\ - & -\end{array}$

$\begin{array}{cc}\text { Sucrose diet } & \text { Dextrose diet } \\ & 8 \\ 2.9 & 6.5 \\ 8.1 & 6.3 \\ 4.3 & I .1 \\ 1.8 & 0.4 \\ 0.3 & 0.1 \\ I 7.4 & 14.4 \\ 6.1 & I .6 \\ \pm 0.5 \quad & \pm 0.9 \\ & \end{array}$

$\mathrm{NS}$, not significant.

was similar with both diets, and Wilcoxon's sum of ranks statistical test showed no significant difference between the plaque scores with the two sugars (Table I).

A much firmer material of a different texture from soft plaque was impacted into both sound and carious fissures in the teeth. This material was usually yellow and fibrous in texture. It appeared to contain material from bedding and hair, and may have been partly the result of coprophagy.

\section{Caries}

The incidence of caries was high in both groups, but the sucrose diet was more cariogenic than the glucose diet. The difference between the mean caries scores (Table 2) was significant at $P<0.05$ after 5 weeks, and highly significant $(P<0.002)$ after 8 weeks (Wilcoxon's sum of ranks test).

Most of the lesions developed in the six main molar fissures. On the sucrose diet $95 \%$ of the fissures were carious after 5 weeks and $97 \%$ after 8 weeks, whereas on the glucose diet the corresponding figures were 79 and $76 \%$ respectively.

Table 3 gives the numbers of lesions at different stages of development, classified according to the system of Shaw et al. (I944). Not only was the mean total number of lesions per rat greater on the sucrose diet than on the glucose diet, but there was also a higher proportion of advanced lesions with sucrose than with glucose.

After 5 weeks very few lesions had advanced to the stage where they were visible as fissure cavities on superficial examination (gross lesions with a score of 3 or more by the system of Shaw et al. (1944), but after 8 weeks such lesions were observed in all the animals on the sucrose diet, and in five out of eight animals on the glucose diet, with a significantly greater number on the sucrose diet $(P<0 \cdot 01$ by Wilcoxon's sum of ranks test). 
After 8 weeks on the diets some 'smooth-surface' caries was observed, shallow and spreading laterally along the gingival margin, with mean scores per rat of 4.4 on the sucrose and 2.8 on the glucose diet, in a total of five rats on each diet.

\section{I SCUSSI ON}

After it had been established that the unit could be operated successfully without contamination, and that the germ-free animals developed no plaque and no caries until transferred to conventional conditions, the results presented in Tables I-3 showed that implantation of Streptococcus IB-I60o into germ-free rats led to the development of plaque and caries on high-sugar diets.

The sugars under test were sucrose and D-glucose at $460 \mathrm{~g} / \mathrm{kg}$ diet, but both diets contained $320 \mathrm{~g}$ Complan $/ \mathrm{kg}$, contributing a further $\mathrm{I} 8 \mathrm{~g}$ sucrose $/ \mathrm{kg}$. In experiments with conventional rats, skim-milk powder (devoid of sucrose or glucose) may be used as the main source of protein, but diets containing skim-milk powder were found to be inadequate for these gnotobiotic animal trials, probably because of the destruction of vitamins by $\gamma$-irradiation in the sterilization of the diet, and the absence of Bvitamins from intestinal synthesis in the gnotobiotic animals. The vitamin content was therefore brought to an adequate level, and the protein content was maintained, by replacing the skim-milk powder by Complan.

In spite of the $18 \mathrm{~g}$ sucrose $/ \mathrm{kg}$ present in the glucose diet, the level of caries was significantly lower than on the sucrose diet, with a smaller total number of lesions and fewer advanced lesions. This is in line with results in conventional animals, but contrasts with Rosen's (1969) findings that a diet containing $560 \mathrm{~g}$ glucose $/ \mathrm{kg}$ produced more caries than a diet containing $5^{60} \mathrm{~g}$ sucrose $/ \mathrm{kg}$ in gnotobiotic rats infected with a Lactobacillus or any of three different strains of streptococci. The present results also conflict with the finding of Fitzgerald (1968) that glucose produced no caries in gnotobiotic animals, but agree with his observation of the high cariogenicity of sucrose. It seems unlikely that these discrepancies can bc explained solely by differences in the bacteria implanted. Rosen found more caries from glucose than from sucrose in the presence of Streptococcus FA-I, whereas Fitzgerald found no caries from glucose in the presence of two strains of streptococci said to be identical with FA-r.

The difference in cariogenicity between the sugars does not appear to result from differences in the amount of plaque formed, since the two sets of plaque scores were not significantly different (Table $\mathrm{I}$ ) and few lesions developed on smooth surfaces where soft plaque accumulated. The hard, yellowish, fibrous material which packed into the molar fissures, where the majority of the lesions developed, was quite unlike the soft coronal plaque in appearance.

The reason why sucrose is more cariogenic than glucose is not known, but it has been observed that some bacteria in plaque can form relatively large quantities of extracellular polysaccharides from sucrose (see Fry \& Grenby, 1972, for references to some of this work). In line with this, some tests in vitro on the metabolism of the Streptococcus strain IB-I600 used in the present work, showed that it synthesized 
more than twice as much polysaccharide in a sucrose-containing medium as in a glucose medium, although it consistently produced more acid from dextrose than from sucrose.

One point which can be investigated in gnotobiotic animal units of this type is the species-specificity of caries-inducing micro-organisms. IB- 1600 is a streptomycinresistant strain of Ingbritt (Krasse, I966) originally isolated from a highly caries-active human mouth. It is biochemically and morphologically similar to hamster cariogenic streptococci, and has previously been found to give rise to rampant caries in the hamster (Edwardsson, 1968). The present results show that under gnotobiotic conditions it is also highly caries-active in the rat.

Thus, these preliminary trials have confirmed that this gnotobiotic system is a practical proposition for testing the caries-activity of specific micro-organisms, and for distinguishing between different carbohydrate foods in terms of their cariogenicity. The variation among previous results and the present work in comparing sucrose and glucose emphasizes the need for further development of these laborious techniques to improve the reproducibility of the results.

We are grateful to Beecham Products (UK), who supported this work, and to the Amalgamated Dental Co Trust Fund for a grant to one of us (F.M.P.). We also thank Mr C. J. Leer and other colleagues who have given us valuable assistance in setting up a germ-free rat unit: the Superintendent, Allington Farm, Ministry of Defence, Porton Down, Wilts., particularly Mr. R. Cook; Mrs M. Barnes, Institute of Child Health, London WCr; Dr D. Blackmore, Medical Research Council Laboratory Animals Centre, Carshalton, Surrey; Dr M. Dinsley and Miss J. Woodnutt, Medical Research Council National Institute for Medical Research, London $\mathrm{NW}_{7}$, and the late Professor R. H. Gorrill and his staff for advice on bacteriological techniques.

\section{REFEREN CES}

Blackmore, D. K. \& Green, R. M. (I97I). Archs oral Biol. 15, I 149.

Cook, R., 'Tuffrey, M. \& Barnes, R. D. (1 g68). Lab. Anim. 2, 5 x.

Dinsley, M. ( 1967$)$. In The UFAW Handbook on the Care and Management of Laboratory Animals $3 \mathrm{rd}$ ed., Ch. I 5, p. 216 [Universities Federation for Animal Welfare]. Edinburgh: Livingstone.

Edwardsson, S. (1968). Archs oral Biol. 13,637.

Fitzgerald, R. J. (1968). Caries Res. 2, 139 .

Fitzgerald, R. J. \& Keyes, P. H. (1960). \%. Am. dent. Ass. 6r, 9.

Fry, A. J. \& Grenby, T. H. (1972). Archs oral Biol. 17, 873 .

Gibbons, R. J., Berman, K. S., Knoettner, P. \& Kapsimalis, B. (1966). Archs oral Biol. 11, 549.

Greene, J. C. \& Vermillion, J. R. (1960). \%. Am. dent. Ass. 6r, I 72.

Grenby, T. H. (1963). Archs oral Biol. 8, 27.

Grenby, T. H. (1967). Helv, odont. Acta II, 43 .

Grenby, T. H. (1970). Br. dent. $\mathcal{~}$, 128, 575 .

Grenby, T. H. (1971). Archs. oral Biol. 16, 631.

Grenby, T. H. \& Hutchinson, J. B. (1969). Archs oral Biol. r4, 373.

Guggenheim, B., König, K. G., Herzog, E. \& Mühlemann, H. R. (ıg66). Helv. odont. Acta Io, Iо .

Gustafson, G., Stelling, M., Abramson, E. \& Brunius, E. (1955). Odont. Tidskr. 63, 506.

Krasse, B. (1965). Archs oral Biol. 1o, 223.

Krasse, B. (1966). Archs oral Biol. I1, 429.

Orland, F. J., Blayney, J. R., Harrison, R. W., Reyniers, J. A., Trexler, P. C., Ervin, R. F., Gordon, H. A. \& Wagner, M. (1955). F. Am. dent. Ass. 50, 259. 
Rosen, S. (1969). Archs oral Biol. 14, 445.

Rosen, S., Lenney, W. S. \& O'Malley, J. E. (1968). F. dent. Res. 47, 358.

Shafer, W. G. (I949). Science, N.Y. I10, I43.

Shaw, J. H., Schweigert, B. S., McIntire, J. M., Elvehjem, C. A. \& Phillips, P. H. (1944). F. Nutr. 28, 333 .

Trexler, P. C. (I964). Scient. Am. 21r, 78.

Zinner, D. D., Jablon, J. M., Aran, A. P. \& Saslaw, M. S. (1966). Archs oral Biol. 11, 1419. 